\title{
REVIEW
}

\section{The role of an anti-diabetic drug metformin in the treatment of endocrine tumors}

\author{
Shilpa Thakur, Brianna Daley and Joanna Klubo-Gwiezdzinska
}

Metabolic Diseases Branch, National Institute of Diabetes and Digestive and Kidney Diseases, National Institutes of Health, Bethesda, Maryland, USA

Correspondence should be addressed to J Klubo-Gwiezdzinska: joanna.klubo-gwiezdzinska@nih.gov

\begin{abstract}
Incidence of endocrine cancers is rising every year. Over the last decade, evidence has accumulated that demonstrates the anti-cancer effects of an anti-diabetic drug, metformin, in endocrine malignancies. We performed a literature review utilizing the PubMed, Medline and clinicaltrials.gov databases using the keyword 'metformin' plus the following terms: 'thyroid cancer', 'thyroid nodules', 'parathyroid', 'hyperparathyroidism', 'adrenal adenoma', 'Cushing syndrome', 'hyperaldosteronism', 'adrenocortical cancer', 'neuroendocrine tumor (NET)', 'pancreatic NET (pNET)', 'carcinoid', 'pituitary adenoma', 'pituitary neuroendocrine tumor (PitNET)', 'prolactinoma', 'pheochromocytoma/ paraganglioma'. We found 37 studies describing the preclinical and clinical role of metformin in endocrine tumors. The available epidemiological data show an association between exposure of metformin and lower incidence of thyroid cancer and pNETs in diabetic patients. Metformin treatment has been associated with better response to cancer therapy in thyroid cancer and pNETs. Preclinical evidence suggests that the primary direct mechanisms of metformin action include inhibition of mitochondrial oxidative phosphorylation via inhibition of both mitochondrial complex I and mitochondrial glycerophosphate dehydrogenase, leading to metabolic stress. Decreased ATP production leads to an activation of a cellular energy sensor, AMPK, and subsequent downregulation of mTOR signaling pathway, which is associated with decreased cellular proliferation. We also describe several AMPK-independent mechanisms of metformin action, as well as the indirect mechanisms targeting insulin resistance. Overall, repositioning of metformin has emerged as a promising strategy for adjuvant therapy of endocrine tumors. The mechanisms of synergy between metformin and other anticancer agents need to be elucidated further to guide well-designed prospective trials on combination therapies in endocrine malignancies.
\end{abstract}

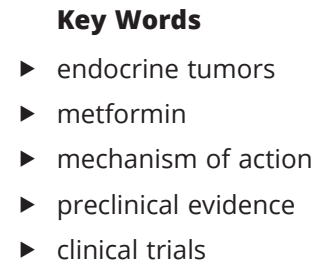

Journal of Molecular Endocrinology (2019) 63, R17-R35

\section{Introduction}

Metformin is a biguanide that has been vastly known as an anti-hyperglycemic drug. Although metformin was initially identified as an anti-diabetic drug, its pleiotropic effects have been recognized over the past several years. Metformin is emerging as a drug with numerous beneficial effects that include body weight control; reduction of the risk for cardiovascular and neuropsychiatric disorders; and treatment of nonalcoholic fatty liver disease, metabolic syndrome and cancer (Zhou et al. 2018, Amin et al. 2019). The anti-cancer potential of metformin 
was first recognized in diabetic patients. These patients treated with metformin were characterized by a lower cancer incidence in comparison to patients who were on other anti-diabetic medications (Schulten 2018). Subsequently, several epidemiological data documented the association between metformin therapy and a lower risk of developing breast, colon, pancreatic and liver cancers in diabetic patients (Andrzejewski et al. 2018). The realization of the anti-cancer potential of metformin initiated a series of investigations to uncover the role of metformin as a potential drug for the prevention and treatment of a variety of cancers (Vancura et al. 2018). To date, several clinical trials have been conducted, with many still ongoing and recruiting patients (https:// clinicaltrials.gov/ct2/home) (Chae et al. 2016). The results for some of these clinical studies are highly encouraging and demonstrate the potential of metformin in the prevention and treatment of various cancer types such as breast, pancreatic, gastric, colorectal, endometrial, prostate and bladder, either alone or in combination with other drugs (Niraula et al. 2012, Spillane et al. 2013, Hawkes et al. 2014, Nayan et al. 2015, Chae et al. 2016, Lee et al. 2016). Based on a meta-analysis that included 13,008 cancer patients with type 2 diabetes, an improvement in overall, and cancer-specific survival was observed in patients treated with metformin in comparison to other glucose-lowering drugs (Yin et al. 2013). Another metaanalysis, which included 65,540 cancer patients with diabetes from 47 independent studies, demonstrated an association of metformin use with a reduction in colon, liver and lung cancer incidence, together with improved survival in all examined cancer types (Gandini et al. 2014). While there is abundant information available showing the efficacy of metformin in multiple cancers, limited information is currently available regarding the effects of metformin on cancers of the endocrine system.

The endocrine system involves a number of hormoneproducing glands that regulate various body functions (Asa \& Mete 2018) (Fig. 1). The most common endocrine tumors arising from endocrine glands include thyroid, parathyroid, pituitary and neuroendocrine tumors of the gastrointestinal system (Zhang \& Nose 2011). Development of cancer in any of these endocrine glands can affect the production of hormones and thus lead to severe consequences. Most of the endocrine tumors tend to be benign; however, some of them become malignant and require extensive therapy. Of note, the incidence of endocrine cancers is increasing every year worldwide (Asa \& Mete 2018). The prognosis of patients with metastatic endocrine cancers is variable, with high mortality rates and suboptimal treatment response in poorly differentiated aggressive tumors of the endocrine

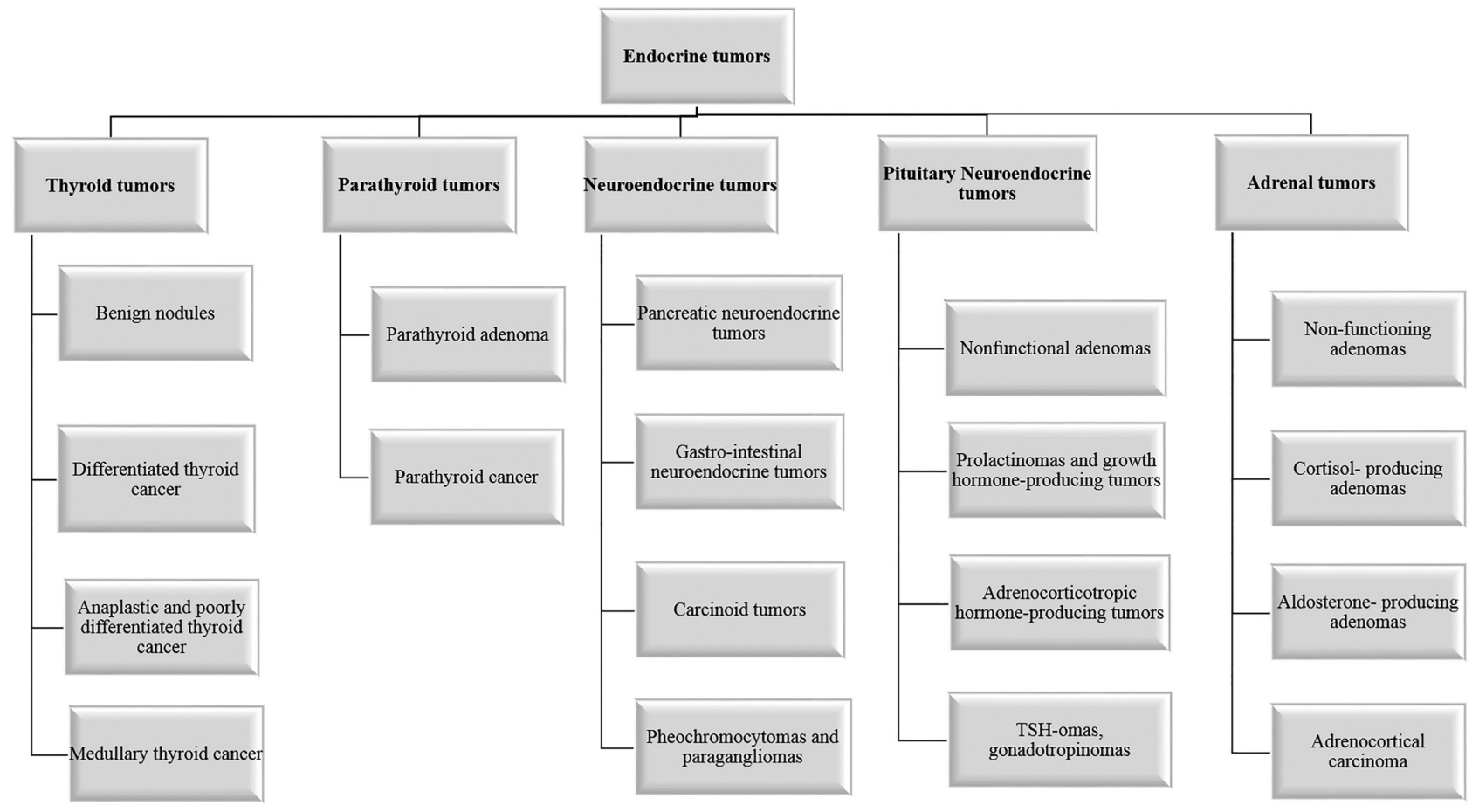

Figure 1

Different types of endocrine tumors. 
system (Lima et al. 2017). The standard-of-care therapy for patients with endocrine tumors varies depending on the origin of the tumor, its nature (benign or malignant), the presence of an overproduction of hormones by the tumor and the tumor stage (metastatic or not). Over the last decade, the growth inhibitory effects of metformin have been observed in patients with endocrine tumors. Although these studies are limited; nonetheless, there is compelling evidence from in vitro and in vivo models that point toward the efficacy of metformin in the treatment of endocrine tumors.

Metformin exhibits its anti-cancer effects through multiple pathways that can be inter-connected or work independently (Vancura et al. 2018). The targets of metformin that were predominately studied include mitochondrial respiratory chain complex I, AMPK and mechanistic target of rapamycin (mTOR) (Sosnicki et al. 2016, Li et al. 2018). These targets are components of biologically important pathways associated with cellular metabolism, proliferation, survival and apoptosis. Besides these, numerous other targets of metformin have been identified in cancer cells such as cyclins (CCND1, CCNE2), miRNAs (miR-26a, miR-34a) and mitochondrial genes (mGPDH) (Schulten 2018). In this review, we discuss the anti-cancer potential of metformin in endocrine tumors and the underlying mechanisms of action.

\section{Differentiated thyroid cancer (DTC)}

\section{Epidemiology}

Thyroid cancer is the most common endocrine malignancy, accounting for more than $90 \%$ of the endocrine cancers. It is the fifth most common cancer in women in the United States (https://www.cancer.org/research/cancerfacts-statistics/all-cancer-facts-figures/cancer-factsfigures-2019.html, Cabanillas et al. 2016). Thyroid cancer can be categorized into two different types based on its origin: epithelial-derived and neuroendocrine C-cellderived thyroid cancer. Epithelial-derived DTC variants include papillary thyroid cancer (PTC), follicular thyroid cancer (FTC) and Hurthle cell thyroid cancer (HTC), while de-differentiated variants include poorly differentiated thyroid cancer (PDTC) and anaplastic thyroid cancer (ATC). Medullary thyroid cancer (MTC) is derived from neuroendocrine C-cells producing calcitonin, which is responsible for calcium balance. Among these types, PTC is the most common subtype of thyroid cancer (Schmidbauer et al. 2017).
In the last few years, the anti-cancer effects of metformin have been identified in thyroid cancer patients. It is particularly interesting in view of the fact that the incidence of thyroid cancer has been reported to be higher in type 2 diabetes mellitus (T2DM) patients (Li \& Qian 2017). Epidemiological evidence has shown the association between T2DM, insulin resistance and cancer (Vigneri et al. 2009). Obesity, which is a risk factor for the development of insulin resistance and T2DM, has also been linked with an increased risk of thyroid cancer (Kitahara et al. 2011). The protective effects of metformin either alone or in combination with JQ1 (an inhibitor of bromodomain-containing protein 4) have been observed in an obesity-induced thyroid cancer mouse model (Park et al. 2016, https://www.cancer.org/ research/cancer-facts-statistics/all-cancer-facts-figures/ cancer-facts-figures-2019.html). In a recent retrospective study based on the Korean population, metformin intake was associated with lower thyroid cancer incidence risk. These protective effects of metformin, however, were only observed in individuals who either were on metformin for longer periods of time or those with a higher cumulative dose of metformin (Cho et al. 2018). Another study, based on a Taiwanese population that included more than 1.4 million T2DM patients who had been exposed to metformin, observed a significantly lower risk of developing thyroid cancer in comparison to those who had never been on metformin. Similar to the above-mentioned Korean study, the individuals who had a higher cumulative dose of metformin or had been on metformin for a longer time duration, had a lower incidence of thyroid cancer (Tseng 2014). In contrast to the aforementioned studies, a case-control analysis based on a UK database showed no association between metformin and thyroid cancer incidence. This study was, however, based on a smaller number of patients on metformin (98 cases and 416 matched controls) (Becker et al. 2015).

Besides lowering the thyroid cancer risk, metformin treatment has been associated with longer disease-free survival in T2DM patients with cervical lymph node metastasis of DTC (Jang et al. 2015). In a retrospective study involving 240 DTC individuals, diabetic patients who were treated with metformin had smaller thyroid cancer size, higher complete response rate and longer progression-free survival in comparison to nonmetformin-treated diabetic patients and non-diabetic thyroid cancer patients matched by age, gender and BMI (Klubo-Gwiezdzinska et al. 2013). 
The potential mechanisms for the growth inhibitory effects of metformin have been elucidated in several preclinical studies.

\section{Preclinical evidence}

Metformin treatment inhibits the growth of thyroid cancer cell lines in vitro (Chen et al. 2012, KluboGwiezdzinska et al. 2013). Treatment with metformin can induce cell cycle arrest in G1 phase and induce apoptosis, thus leading to a reduction in cellular viability (Chen et al. 2012). Metformin-mediated AMPK activation leading to the downregulation of p70S6K/pS6 expression is one of the underlying mechanisms for the suppression of thyroid cancer cell growth (Klubo-Gwiezdzinska et al. 2013). AMPK is an energy sensor and a major regulator of cellular energy homeostasis. AMPK is activated under energy stress conditions when ATP levels drop within the cell. Under such circumstances, the major energyconsuming processes, such as cellular proliferation, need to be inhibited (Motoshima et al. 2006). Metformin, which is a well-known mitochondrial complex 1 inhibitor, increases the AMP/ADP ratio within the cell resulting in AMPK activation, which initiates a series of events to preserve energy within the cell (Choi \& Park 2013). AMPK activation is believed to activate the downstream target tuberous sclerosis complex 2 (TSC2), which in turn inhibits the mammalian target of rapamycin (mTOR) signaling pathway (Plews et al. 2015). Since p70S6K/pS6 is downstream of mTOR, inhibition of mTOR hampers their activation leading to reduced protein synthesis, which is necessary for cancer cell growth (Lei et al. 2017). This metformin-induced reduction in p70S6K activation has also been demonstrated in a small set of thyroid tumor samples collected from the metformin-treated thyroid cancer patients (Klubo-Gwiezdzinska et al. 2013).

In an athymic mouse model, metformin treatment inhibited the growth of PTC and promoted necrosis of established tumors. These anti-tumorigenic effects of metformin were associated not only with the activation of AMPK but also with the suppression of AKT signaling pathway (Cho et al. 2014). Metformin-mediated AMPK activation has been shown to inhibit the phosphorylation of insulin receptor substrate-1 (IRS-1). IRS-1 is a downstream mediator of insulin-like growth factor 1 receptor (IGF-1R), which transmits signals from the IGF-1R to the PI3K/AKT pathway (Pierotti et al. 2013). Metformin treatment phosphorylates an inhibitory serine residue on the IRS-1, which blocks its signaling to AKT, thus leading to the suppression of the AKT signaling pathway (Zakikhani et al. 2010). mTOR is also a downstream target of AKT, which suggests its dual suppression by inhibition of AKT signaling and activation of the AMPK pathway (Pierotti et al. 2013). IRS-1 is also a substrate for insulin signaling and metformin-mediated inhibition of IRS-1 blocks insulin/IGF1/AKT/mTOR signaling pathway and protects against insulin-associated cancer progression (Saini \& Yang 2018).

In a recent study published by our group, mGPDH (mitochondrial glycerophosphate dehydrogenase) was identified as a metformin target in thyroid cancer cells (Thakur et al. 2018). mGPDH is an enzyme present on the outer surface of the inner mitochondrial membrane and is part of the glycerol-3-phosphate shuttle. Originally, mGPDH was identified as a metformin target in the liver, inhibiting hepatic gluconeogenesis in a rat model (Madiraju et al. 2014). The primary function of this enzyme is to transfer electrons generated during glycolysis in the cytosol to the mitochondrial electron transport chain. mGPDH, along with its cytosolic counterpart (cGPDH), forms an important link between glycolysis and oxidative phosphorylation (Mracek et al. 2013). Our study revealed that inhibiting mGPDH activity and expression is associated with a reduction in oxidative phosphorylation, which has a negative impact on thyroid cancer cell growth (Thakur et al. 2018). The in vivo experiments in thyroid cancer metastatic mouse models demonstrated that thyroid tumors characterized by higher mGPDH expression were much more sensitive to metformin effects in comparison to low-mGPDHexpressing tumors. Moreover, mGPDH as a metformin target is overexpressed in patient-derived thyroid cancer samples compared with normal tissue (Thakur et al.2018). These studies document that metformin is an inhibitor of mitochondrial function, which affects mitochondrial respiration through inhibition of mitochondrial complex 1 and mGPDH. In a separate study, metformin treatment inhibited glucose uptake by PTC cells both in vitro and in vivo. This reduction in glucose uptake was associated with decreased expression of HK2 and GLUT1 genes (Shen et al. 2017). Altogether, these studies demonstrate that metformin can target cellular metabolism by multiple mechanisms in thyroid cancer cells. However, the effect size observed in vitro with supra-therapeutic metformin concentrations might not be translated to a similar effect size in vivo in humans (Table 2). 


\section{The effects of metformin on hormone overproduction in thyroid cancer}

While DTC is not routinely associated with a significant overproduction of hormones, metastatic FTC may produce excess thyroid hormones leading to signs and symptoms of thyrotoxicosis (Sharma et al. 2011). There are no data showing the role of metformin in the regulation of the production of thyroid hormones in thyroid cancer patients. In a prospective study performed on patients with insulin resistance, while the thyroid hormone levels were still within normal range, a small but significant increase in free triiodothyronine levels was observed in patients receiving metformin (Anil et al. 2016). Also, in an in vivo study performed on male rats, metformin treatment resulted in an increase in the levels of free triiodothyronine (FT3) and free thyroxine (FT4), as well as a slight reduction in thyrotropin (TSH) levels (An et al. 2017).

Metformin also has an important role in the indirect regulation of insulin signaling, which is a growth stimulus of thyroid cancer. The presence of higher insulin levels, typically seen in insulin resistance, has been associated with higher thyroid cancer risk (Rezzonico et al. 2009). DTC expresses IGF-1R which has a high similarity with the insulin receptor (IR) and responds to insulin stimulation. The presence of higher insulin levels can promote the growth of DTC through IGF-1R (Vella et al. 2001). In addition to this, insulin can also enhance the growthpromoting effects of thyroid-stimulating hormone (TSH). The presence of higher TSH levels has been associated with the development and progression of thyroid cancer, but TSH alone has limited tumorigenic potential. The presence of growth factors, such as insulin or insulin-like growth factor (IGF) along with TSH, has been shown to augment the growth of thyroid cancer cells to a much greater extent (Vella et al. 2001, Boelaert 2009). Metformin treatment is associated with a reduction in circulating insulin levels, which suggests its role in the inhibition of thyroid cancer growth by antagonizing the growth-promoting action of insulin (Dowling et al. 2012). This is also supported by an in vitro study in which metformin treatment abolished the growth-promoting effects of insulin on ATC cell lines (Chen et al. 2012).

\section{Prospective clinical trials}

There are currently two clinical trials utilizing metformin in the management of thyroid cancer. One study, currently open for enrollment, is focused on metformin therapy as an add-on to treatment with radioactive iodine (NCT03109847). This study is designed to assess if metformin can mitigate the myelosuppressive effects of radioactive iodine (RAI), which is used for the therapy of DTC. There is an evidence from retrospective studies that metformin attenuates the RAI-induced decrease in peripheral blood cells in patients with DTC (Bikas et al. 2016).

The second study, which has been completed, was testing the role of metformin in suppressing TSH levels in thyroid cancer patients. Fifty patients, whose levothyroxine dose was reduced by $30 \%$, were randomized to metformin $500 \mathrm{mg}$ daily or placebo. After 3 months of therapy, there was no difference in TSH levels between the groups, suggesting no benefit of brief exposure to a minimal dose of metformin in the reduction of TSH concentration (Mousavi et al. 2014).

\section{Medullary thyroid cancer (MTC)}

\section{Epidemiology}

MTC originates from the parafollicular C-cells of the thyroid gland. It is a rare type of cancer, with only $3-5 \%$ of thyroid cancer patients diagnosed with this neuroendocrine tumor. MTC is characterized by a high prevalence of central and lateral neck lymph node metastases; thus, appropriate extensive surgery is the best therapeutic option to achieve remission. However, the locoregional recurrence rate is high and, once the disease presents with distant metastases, the routine management consists of therapy with tyrosine kinase inhibitors (TKIs) (Accardo et al. 2017), which does not lead to complete remission but extends the time to progression. At present, there is no clinical information available regarding the use of metformin in these patients, mostly because of the rare occurrence of this disease.

\section{Preclinical evidence}

There are a few in vitro studies that have determined the anti-cancer effects of metformin on the MTC-derived cell lines. A study published in 2017 analyzed the growth inhibitory effects of metformin on a variety of thyroid cancer cell lines with different origins - FTC, PTC, ATC and MTC - and normal thyroid follicular cells. Irrespective of the origin of thyroid cancer cell lines, metformin suppressed cellular proliferation at concentrations that fall within the therapeutic range (Kheder et al. 2017). In another study, the anti-cancer effects of metformin were 
tested in two MTC cell lines, TT and MZ-CRC-1. The authors reported inhibition in cancer cell growth as well as a reduction in the ability to form spheroids. This study also demonstrated metformin-induced inhibition of the mTOR-p70S6K signaling pathway, downregulation of p-ERK activation and decreased expression of cyclin-D1 in MTC cells (Klubo-Gwiezdzinska et al. 2012). These in vitro observations were also supported by human MTC samples characterized by higher expression of metformin targets - cyclin D1 and mTOR-p70S6K in comparison to the corresponding normal tissues (Klubo-Gwiezdzinska et al. 2012). The metformin-induced growth inhibitory effects in this study were found to be independent of AMPK activation.

mTOR is known to be activated by multiple pathways, among which the PI3K/AKT pathway is the most common. However, in the aforementioned study, metformin treatment did not inhibit AKT activation as is revealed by the analysis of p-AKT levels in the MTC cell lines. This indicates inhibition of mTOR by another pathway. Activation of ERK (p-ERK) has also been shown to activate the mTOR signaling pathway either by inhibiting TSC2 or by phosphorylation of RAPTOR protein (regulatoryassociated protein of $\mathrm{mTOR}$ ), both of which promotes mTOR signaling (Mendoza et al. 2011). Metformin treatment has been shown to lower p-ERK levels in MTC as well as in certain DTC cell lines (Klubo-Gwiezdzinska et al. 2012, 2013).

\section{The role of metformin on hormone overproduction in MTC}

MTC is known to produce calcitonin, which is used as a tumor biomarker and a prognostic factor in the surveillance of MTC patients. Significantly elevated calcitonin may lead to calcium imbalance as well as promote intestinal peristalsis leading to severe diarrhea. There are no studies looking at the effect of metformin on calcitonin production by MTC cells.

One of the most debilitating complications of metastatic MTC is ACTH-dependent Cushing syndrome due to the overproduction of ACTH by MTC cells, stimulating a cortisol release from the adrenal glands. At present, there is no information on the effects of metformin on ACTH production by MTC cells.

\section{Clinical trials}

There are currently no clinical trials investigating the role of metformin in MTC.

C) 2019 Society for Endocrinology Published by Bioscientifica Ltd. Printed in Great Britain

\section{Anaplastic thyroid cancer (ATC)}

\section{Epidemiology}

ATC is a rare type of thyroid malignancy but is associated with a very high mortality rate. It is one of the most lethal cancers and is associated with extremely poor prognosis (Limaiem \& Giwa 2019). ATC accounts for 2-3\% of all thyroid malignancies. The first-line treatment for ATC patients includes surgical resection followed by high-beam radiation therapy and chemotherapy. Patients with ATC have a very short median survival of around 6 months (Saini et al. 2018). ATC is resistant to most standard treatments, which makes its management enormously difficult. However, recently, combination therapy with dabrafenib (BRAF inhibitor) and trametinib (MEK inhibitor) led to an objective response in $69 \%$ of patients with locally advanced or metastatic ATC, leading to the FDA approval of this combination therapy for ATC (Subbiah et al. 2018).

At present, there is no clinical information available regarding the effects of metformin on the management of ATC.

\section{Preclinical evidence}

In the in vitro studies performed on anaplastic thyroid cancer cell lines, metformin treatment resulted in the reduction of cellular proliferation and the induction of apoptosis (Chen et al. 2012, Nozhat et al. 2018). Metformin treatment can also inhibit cell migration and affect the morphology of ATC cells (Nozhat et al. 2018). In another study, the addition of metformin improved the growth inhibitory effects of sorafenib (a multi-kinase inhibitor) on ATC cell lines. The combination of metformin with sorafenib resulted in increased apoptosis and cell cycle arrest in ATC cells in comparison to treatment with either metformin or sorafenib alone. The growth inhibition in these cells was associated with inhibition of the ERK signaling pathway (Chen et al. 2015). In a similar study, the combination of metformin with vemurafenib (a BRAFV600E inhibitor) resulted in an increased loss of cell viability and apoptosis in ATC and PTC cells in comparison to treatment with either metformin or vemurafenib alone (Hanly et al. 2015).

At present, there is no strong evidence elucidating the mechanism of metformin action in ATC cells. Moreover, the above observations need to be validated in animal models.

\section{Clinical trials}

There are currently no clinical trials investigating the role of metformin in ATC. 


\section{Benign thyroid nodules}

\section{Epidemiology}

Thyroid nodules are very common and nearly $90 \%$ of thyroid nodules are benign in nature (Durante et al. 2018). The most common risk factors for developing thyroid nodules include age, gender, family history of thyroid nodules and radiation exposure. Besides these, the other important risk factors that have been associated with an increased incidence of thyroid nodules are obesity, diabetes, insulin resistance and metabolic syndrome (Duran et al. 2014, Tang et al. 2017, Buscemi et al. 2018, Moon et al. 2018). One or more of these risk factors are usually associated with each other and the presence of one risk factor can promote the appearance of another. Metformin use has been associated with the management of all these risk factors (Fournier et al. 2014, Zhou et al. 2018).

In a patient-based prospective study that included 66 women with small benign thyroid nodules and insulin resistance, metformin treatment $(500 \mathrm{mg} /$ twice a day/6 months) resulted in a significant (30\%) reduction in nodule size in comparison to non-metformin-treated women. A combination of levothyroxine with metformin had resulted in an even better outcome in these patients with a 55\% reduction in their nodular size (Rezzonico et al. 2011). In a prospective study that included 100 patients with insulin resistance, metformin therapy resulted in a significant reduction in BMI, insulin resistance, thyroid volume and thyroid nodule size (Anil et al. 2016).

In a recently published meta-analysis study that included 240 patients from three randomized control trials and four prospective studies, metformin treatment caused a decrease in nodular volume, TSH level and improvement in the insulin resistance in these patients (Sui et al. 2018). Another very recent meta-analysis, including 189 patients fulfilling the analysis criteria, provided similar conclusions (He et al. 2019).

\section{Preclinical evidence}

To the best of our knowledge, there is no preclinical information available regarding the effects of metformin on benign thyroid nodules or on the cells derived from them.

\section{Clinical trials}

In Brazil, a clinical trial is currently ongoing to examine the effects of insulin resistance and the use of metformin on the volume of thyroid nodules (NCT03183752).
In a completed clinical trial performed on 89 prediabetic patients, metformin treatment resulted in a significant reduction in the volume of small solid nodules in comparison to placebo-treated patients. No significant effect of metformin was observed on the mixed solidcystic nodules. In addition, metformin treatment resulted in a decrease in TSH levels in patients with TSH $>2.5 \mu \mathrm{U} / \mathrm{mL}$. Metformin treatment was also associated with lower thyroid gland volume compared with the placebo group (Karimifar et al. 2014).

\section{Parathyroid tumors}

Parathyroid tumors are relatively common, affecting around 30 people in 100,000 population (Thakker 2016). The most common type of parathyroid tumors are adenomas, which are benign in nature. Parathyroid tumors can cause hyperparathyroidism due to the overproduction of parathyroid hormone (PTH) leading to bone resorption, hypercalcemia and its clinical consequences. The other type of parathyroid tumor is a carcinoma, a very aggressive malignancy, which luckily accounts for less than $1 \%$ of parathyroid tumors (DeLellis 2011). The most common treatment for PTHhypersecreting carcinomas and adenomas is surgery. Interestingly, there are reports suggesting the association between hyperparathyroidism and insulin resistance and reversal of insulin resistance measured by HOMA-IR index post-curative parathyroidectomy (Duran et al. 2017). Moreover, Tanaka et al. showed that parathyroid tumor tissues express IGF-binding proteins and, based on in vitro experiments, suggested that the IGF-1 and IGFbinding proteins are involved in the growth regulation of parathyroid tumor cells (Tanaka et al. 1994). The latter observation may form a basis for exploring the indirect effects of metformin on insulin signaling in these tumor models. However, at present, there is no epidemiological, preclinical or clinical data available on the role of metformin in parathyroid tumors.

\section{Neuroendocrine tumors (NETs)}

\section{Epidemiology}

Neuroendocrine tumors (NETs) represent a heterogeneous group of tumors that originate from cells with both neural and endocrine properties. NETs can be classified into different types based on their site of origin. The most common types of NETs are gastrointestinal NETs (GI-NETs), pancreatic neuroendocrine tumors (pNETs) 
and lung carcinoids (Oronsky et al. 2017, Patel \& Galoian 2018). The prevalence of NETs is on the rise (Dasari et al. 2017). At present, the treatment options for these patients include curative surgery, treatment with both somatostatin analogs (SSA) and radiolabeled SSAs, as well as targeted treatment with tyrosine kinase inhibitors and mTOR pathway inhibitors (Young et al. 2015).

Diabetes is an independent risk factor for the development of pNETs and GI-NETs (Hassan et al. 2008, Halfdanarson et al. 2014, Haugvik et al. 2015). The therapeutic effects of metformin have been reported in patients with diabetes suffering from concurrent pNETs (Pusceddu et al. 2016). In a recent retrospective study conducted in Italy, metformin treatment was associated with longer progression-free survival (PFS) in diabetic patients with pNETs in comparison to diabetic patients or non-diabetic patients who were not receiving metformin. This study also reported a significant improvement in PFS of pNET patients when metformin was implemented as an adjunct to combination therapy with everolimus (mTOR inhibitor) and SSAs (octreotide or lanreotide) or with SSAs alone (Pusceddu et al. 2018). At present, there are no clinical studies analyzing the effects of metformin in NETs other than pNETs.

\section{Preclinical evidence}

In a recent study performed on pNET cells (BON-1 and QGP-1), metformin treatment inhibited cellular viability in both cell lines in a time-dependent manner. The mechanism of growth inhibition was associated with reduction in p-AKT and p-ERK levels in BON-1 cells, but not in QGP-1 cells (Herrera-Martínez et al. 2019). In another study, metformin treatment inhibited the cellular proliferation of neuroendocrine tumor cells of different origins in a dose-dependent manner (Vlotides et al. 2014). Depending upon the origin of the cell lines (pancreatic neuroendocrine cells - BON1, midgut carcinoid cells - GOT1 and bronchopulmonary neuroendocrine cells - NCI-H727), the underlying mechanism for metformininduced growth inhibition varied. However, regardless of their origin, metformin treatment suppressed mTOR signaling in all cell lines. Conversely, other metformininduced effects, such as AMPK activation/inhibition and apoptosis induction, were dependent on cell line origin. This study also demonstrated glycogen synthase kinase 3 (GSK) as a metformin target in BON1, GOT1 and NCI-H727 cells (Vlotides et al. 2014). GSK is a serinethreonine protein kinase that plays an important role in multiple processes such as cellular proliferation, differentiation, apoptosis, metabolism, immunity and autophagy. GSK has two isoforms - GSK-3 $\alpha$ and GSK-3 $\beta$ - that are constitutively active within the cells unless being inactivated by their phosphorylation. GSK-3 has multiple downstream targets by which it can regulate cell proliferation and survival processes. GSK-3 activity has been associated with tumorigenesis and has been investigated as a potential target in the treatment of cancer (Mancinelli et al. 2017). Metformin treatment suppressed GSK-3 activity by promoting its phosphorylation in all three NET cell lines (BON1, GOT1, NCI-H727) (Vlotides et al. 2014). In another study, GSK-3 $\alpha / \beta$ has been demonstrated as a therapeutic target in NETs. Treatment with a GSK-3 inhibitor led to a reduction in cellular viability, induction of apoptosis and inhibition of the migration potential in NET cell lines (BON1, QGP1, H727) (Aristizabal Prada et al. 2018). Diminished oncogenic growth in these cell lines upon GSK-3 inhibition was associated with the inhibition of mTOR and EGFR signaling pathways. However, the detailed mechanism by which metformin inhibits GSK-3 is not understood and needs to be determined.

\section{Clinical trials}

To further confirm these observations and to establish the anti-tumorigenic effects of metformin, a prospective phase II trial (NCT02294006) is underway, testing the efficacy of metformin in combination with everolimus (mTOR inhibitor) and octreotide (SSA) in Fondazione IRCCS Istituto Tumori, Italy. A pilot phase II clinical trial (NCT02279758) is also being conducted in Instituto do Cancer do Estado de São Paulo, Brazil to test the treatment efficacy of metformin in patients with gastroenteropancreatic NETs. Besides this, a phase I trial (NCT02823691) is ongoing at the National Cancer Institute, Italy to assess the safety of metformin in combination with another SSA, lanreotide, in patients with gastrointestinal or lung NET carcinoids.

\section{Tumors of the adrenal medulla: pheochromocytomas (PCC) and paragangliomas (PGL)}

\section{Epidemiology}

Pheochromocytomas and paragangliomas are rare neuroendocrine tumors with an incidence rate of approximately 2-8:1,000,000/year. While PCCs arise from the chromaffin cells of the adrenal medulla, PGLs originate from the ganglia located outside of the adrenal 
gland (Fishbein \& Nathanson 2012). These tumors are mostly benign, but their malignant transformation does happen. Since the incidence of these tumors is so rare, at present, there is no patient-related information available on the efficacy of metformin treatment on these tumors.

\section{Preclinical evidence}

There are a few in vitro studies performed on the cell lines derived from PCC/PGL tumors that demonstrate the antiproliferative potential of metformin. As is reported in thyroid cancer and NET cell lines, metformin exposure inhibited cell proliferation, promoted cell cycle arrest and apoptosis of pheochromocytoma rat-derived cells (PC12 cell line) (Li et al. 2017). This study demonstrated activation of the AMPK and inhibition of the mTOR and ERK signaling pathways upon metformin treatment. The inhibition of mTOR can occur through activation of the AMPK pathway. Moreover, there was a downregulation of Ccna2 and Ccnb2 expression, which plays an important role in the regulation of cell cycle progression (Li et al. 2017). A similar study was conducted on the adherent version of the PC12 cell line (PC12-Adh PHEO), which also demonstrated growth inhibition upon metformin treatment (Meireles et al. 2017). Moreover, metformininduced a reduction in oxygen consumption, which was most likely associated with the inhibition of mitochondrial respiration (Meireles et al. 2017). These metformin-associated effects need to be validated on human PCC-derived cell lines.

Cell lines derived from head and neck PGLs (PTJ64i and PTJ86i) are also sensitive to metformin-mediated growth suppression. In combination with a pyruvate dehydrogenase kinase inhibitor, dichloroacetate, and a PPAR $\alpha$ antagonist, GW6471, metformin had synergistic effects on the cellular viability and clonogenicity of these cell lines (Florio et al. 2018). Such combination treatments might be effective in these tumors when the chemotherapy treatments are not effective and surgery rendering the patient as 'no evidence of disease NED' is not feasible.

It will be interesting to establish if these in vitro observations can be confirmed through animal models and human studies.

\section{The role of metformin on hormone overproduction in PCCs/PGLs}

To the best of our knowledge, there are currently no preclinical or clinical data on the association between metformin and overproduction of catecholamines by pheochromocytomas/paragangliomas.

\section{Clinical trials}

There are currently no clinical trials addressing the role of metformin in the management of metastatic pheochromocytomas/paragangliomas.

\section{Tumors of the adrenal cortex: adrenocortical adenoma/adrenocortical carcinoma (ACC)}

\section{Epidemiology}

Adrenocortical adenomas are the most common types of adrenal tumors and are benign in nature. These tumors can be functionally inactive or actively produce cortisol, aldosterone or androgens. The non-functional adenomas are usually left untreated unless they are large and growing, in which case surgery is indicated, whereas functional adenomas can be treated by their surgical removal and/or by medications that control the activity/ production of hormones. In contrast to adenomas, ACCs are extremely rare in occurrence, affecting 1-2 people per million population. ACCs are malignant and lethal in nature and can be associated with a significant overproduction of hormones - particularly androgens leading to signs and symptoms of virilization in affected women. The most common treatment for ACCs is surgery and chemotherapy (Else et al. 2014).

Clinically, not much information is available related to the effects of metformin on the treatment of adenomas or ACCs. Nonetheless, there is a recent case study in which the anti-cancer effects of metformin were observed in a metastatic ACC patient. The patient was treated with mitotane in combination with other chemotherapeutic drugs, which resulted in stable disease. This was followed by metformin treatment $(500 \mathrm{mg} / \mathrm{twice}$ a day) in combination with mitotane, which resulted in the further reduction of the nodule size, with a continued response to this combination therapy for nine months (Peixoto et al. 2018).

\section{Preclinical evidence}

To the best of our knowledge, there is only one preclinical study where the effects of metformin have been tested on ACCs through in vitro and in vivo experiments. The study analyzed the growth inhibitory effects of metformin on an adrenocortical cell line, H295R. Metformin treatment 
significantly reduced the cellular proliferation and viability of these cells by inhibiting phosphorylation of ERK1/2 and mTOR, along with activation of the AMPK pathway. In addition to this, metformin treatment promoted apoptosis of these cells by inhibiting the expression of anti-apoptotic genes that led to the activation of caspase 3. These in vitro findings were also confirmed in vivo, where metformin treatment resulted in the inhibition of tumor growth as confirmed by the reduction in Ki67 levels (Poli et al. 2016).

\section{The role of metformin on hormone overproduction in adrenocortical adenomas/ACCs}

At present, there is no information related to the effects of metformin on the cortisol and aldosterone production by adenomas/ACCs.

\section{Clinical trials}

There are currently no clinical trials investigating the role of metformin in adenomas/ACCs.

\section{Pituitary neuroendocrine tumors (PitNETs)}

\section{Epidemiology}

PitNETs, also known as pituitary adenomas (PAs), are the most common tumors of the central nervous system. They are extremely diverse, depending on their cell of origin, and are categorized based on the hormone that they secrete. These PitNETs are usually benign in nature and can be classified as functional or non-functional, depending on whether or not they secrete hormones (Theodros et al. 2015). Among the PitNETs, prolactinomas are the most common, comprising $32-51 \%$ of all PitNETs. Other common PitNETs include non-functioning adenomas, growth hormone (GH)-secreting PitNETs and adrenocorticotropic hormone (ACTH)-secreting PitNETs. Some rare occurring PitNETs, include TSH- and gonadotropin-secreting PitNETs (Mehta \& Lonser 2017). The most common treatment for these patients is medical therapy (treatment of choice for prolactinomas) or surgical treatment, depending on the type of PitNETs. In cases where medical therapy fails, surgical resection is the only option. There are case reports suggesting that such patients may benefit from metformin treatment, as reported in a recent study where the anti-tumorigenic effects of metformin were observed in two patients with prolactinomas who were resistant to bromocriptine, a dopamine agonist.
Combination treatment of bromocriptine and metformin in these patients lowered prolactin levels and reduced the tumor size, while bromocriptine alone was insufficient to reduce the tumor growth (Liu et al. 2018).

\section{Preclinical evidence}

Currently, there are limited studies suggesting the growth inhibitory effects of metformin on PitNETs. The antiproliferative effects of metformin have been seen on an ACTH-secreting mouse corticotroph tumor cell line, AtT20, and growth hormone-secreting PitNET cell lines GH3 and GH1 (An et al. 2017, Faggi et al. 2018, Jin et al. 2018). Besides growth inhibition, metformin-induced apoptosis in the cells by upregulating the expression of pro-apoptotic genes and downregulating the expression of anti-apoptotic genes. In ACTH-secreting AtT20 cells, metformin inhibited cell proliferation by activating the AMPK signaling pathway and inhibiting the IGF-1R/AKT/mTOR pathway. In a recently published study performed on primary cell cultures derived from PitNETs, metformin treatment inhibited cell viability in ACTH-secreting adenomas and non-functioning PAs but not in GH-secreting adenomas and prolactinomas (Vázquez-Borrego et al. 2019).

In a study performed by Faggi et al. (2018) on GH-secreting PitNET cells, metformin treatment mediated the activation of AMPK, with inhibition of the mTOR-p70S6 kinase pathway suggested as the underlying mechanism. However, in the other study conducted by An et al. (2017) on GH3 cells, the underlying mechanism for growth inhibition was associated with increased ATF3 signaling and inhibition of STAT3 activity. These in vitro observations were also validated on a xenograft mouse model. ATF3 is a transcription factor that is induced by physiological stress. Metformin-mediated inhibition of mitochondrial respiration leads to oxidative stress, which in turn can stimulate ATF3 activity. ATF3 induction has been implicated in both the repression and activation of apoptosis in cancer cells, suggesting its dual role (Yin et al. 2008). In GH3 cells, inhibition of ATF3 activity prevented metformin-induced apoptosis, which suggests its tumor suppressor role in PitNET cells. Similar to ATF3, STAT3 can also promote or inhibit cancer cell growth (Avalle et al. 2017). Metformin-mediated STAT3 inhibition suggests its anti-oncogenic role in PitNETs; however, further studies are required to understand the detailed mechanism by which metformin regulates the growth of these tumor cells. 
Table 1 The table summarizes the effects of metformin on different endocrine tumors as reported in various clinical studies.

\begin{tabular}{ll}
\hline $\begin{array}{l}\text { Endocrine tumors } \\
\text { Thyroid cancer }\end{array}$ & Reference \\
Thyroid cancer & Tseng 2014 \\
Thyroid cancer & Becker et al. 2015 \\
Thyroid cancer & Jang et al. 2015 \\
& \\
Thyroid cancer & $\begin{array}{c}\text { Klubo-Gwiezdzinska } \\
\text { et al. } 2013\end{array}$
\end{tabular}

Benign thyroid Rezzonico et al. 2011 nodules

\section{Benign thyroid nodules \\ Benign thyroid nodules}

Thyroid nodules Anil et al. 2016

Thyroid nodules He et al. 2019

Thyroid nodules Karimifar et al. 2014

PNET

Pusceddu et al. 2018

NET

NCT02294006

\section{Study design \\ Retrospective study including diabetic patients (metformin users vs non-users) \\ Retrospective study including diabetic subjects (metformin ever-users vs never-users) \\ Retrospective study including diabetic subjects (metformin ever-users vs never-users) \\ Retrospective study including diabetic patients with DTC (metformin users vs non- users)}

Retrospective study (diabetic patients with thyroid cancer vs control patients with thyroid cancer)

Prospective study in women with insulin resistance and thyroid nodular hyperplasia

Meta-analysis

Clinical trial evaluating the effects of metformin on the volume of benign thyroid nodules

Prospective study on patients with insulin resistance

Meta-analysis performed on patients with thyroid nodules and insulin resistance

Clinical trial evaluating the effects of metformin on thyroid function of prediabetic patients

Retrospective study in patients with advanced pNETs (Diabetic patients on metformin vs diabetic patients on other treatment vs non-diabetic patients)

Clinical trial evaluating the effects of metformin in combination with everolimus and octreotide LAR in patients with advanced well-differentiated pNETs

Metformin dose
Variable; mean dose:
531 mg/daily

Variable

Variable

Variable; Mean dose: 979 mg/day

Variable

Two 500 mg doses/ day

Variable

$500 \mathrm{mg} /$ three times a day

$1700 \mathrm{mg} /$ day for 6 months

Variable

Starting dose: $500 \mathrm{mg} /$ day to be increased to the maximum of 1500 mg/day

Variable

Unknown

\author{
Study endpoint \\ Reduction of thyroid cancer \\ risk in metformin users \\ Reduction of thyroid cancer \\ risk in metformin users \\ No effect of metformin on \\ thyroid cancer risk
}

Metformin use was associated with longer disease-free survival in patients with cervical lymph node metastasis of DTC

Diabetic patients who were on metformin had smaller tumors in comparison to non-metformin users and control thyroid cancer patients

Reduction in the size of the nodules in patients treated with either metformin alone or in combination with levothyroxine

Reduction in nodular size, improvement in thyroid function and insulin resistance

Undergoing

Reduction in body-mass index, insulin resistance, thyroid volume and thyroid nodule size

Reduction in thyroid nodule size, TSH levels and insulin resistance

Decrease in TSH levels in patients with TSH $>2.5 \mu \mathrm{U} / \mathrm{ml}$; reduction in volume of small solid nodules only; inhibits an increase in thyroid volume Improved progression-free survival in metformin-using diabetic patients in comparison to diabetic patients on other treatments and non-diabetic patients Unknown status 
Table 1 Continued.

\begin{tabular}{|c|c|c|c|c|}
\hline Endocrine tumors & Reference & Study design & Metformin dose & Study endpoint \\
\hline NET & NCT02823691 & $\begin{array}{l}\text { Clinical trial evaluating the } \\
\text { safety of lanreotide ATG in } \\
\text { combination with metformin } \\
\text { in gastrointestinal or lung } \\
\text { carcinoids patients }\end{array}$ & $\begin{array}{l}\text { Starting } \\
\text { dose- } 850 \mathrm{mg} / \text { day to } \\
\text { be increased to the } \\
\text { maximum of } \\
2550 \mathrm{mg} / \text { day }\end{array}$ & Undergoing \\
\hline NET & NCT02279758 & $\begin{array}{l}\text { Clinical trial evaluating the } \\
\text { effects of metformin on } \\
\text { patients with well- } \\
\text { differentiated NETs }\end{array}$ & 850 mg/twice a day & Unknown \\
\hline$A C C$ & Peixoto et al. 2018 & $\begin{array}{l}\text { Case study in a patient with } \\
\text { metastatic ACC }\end{array}$ & 500 mg/twice a day & $\begin{array}{l}\text { Reduction in the size of the } \\
\text { adrenal tumor }\end{array}$ \\
\hline Prolactinoma & Liu et al. 2018 & $\begin{array}{l}\text { Retrospective analysis of two } \\
\text { patients with prolactinomas } \\
\text { treated with bromocriptine } \\
\text { and metformin }\end{array}$ & 1.5 g/day & $\begin{array}{l}\text { Reduction in tumor size and } \\
\text { prolactin levels }\end{array}$ \\
\hline
\end{tabular}

ACC, adrenocortical carcinoma; ACTH, adrenocorticotropic hormone; ATC, anaplastic thyroid cancer; DTC, differentiated thyroid cancer; MTC, medullary thyroid cancer; NET, neuroendocrine tumors; PCC, pheochromocytoma; PGL, paraganglioma; PNET, pancreatic neuroendocrine tumors; PTC, papillary thyroid cancer; TSH, thyroid-stimulating hormone.

\section{The role of metformin in hormone production by PitNETs}

At present, there are no clinical data available describing the role of metformin in the regulation of hormone production by functional PitNETs. However, in the abovementioned in vitro studies, metformin suppressed the production of ACTH and GH in pituitary tumor cell line models (An et al. 2017, Jin et al. 2018). On the contrary, metformin treatment did not affect hormone secretion in primary cells derived from either ACTH-secreting, GH-secreting or prolactin-secreting PitNETs (VázquezBorrego et al. 2019).

Metformin treatment has been shown to lower TSH levels in diabetic patients, but the exact mechanism is not understood (Fournier et al. 2014).

\section{Clinical trials}

Currently, there is only one ongoing clinical trial (NCT02060383) focused predominantly on metformin as an agent ameliorating the side effects from the medical management of ACTH-secreting and GH-secreting PAs. This is a phase IV, multi-center, randomized, open-label study of patients treated with the SST analog pasireotide for Cushing disease or acromegaly. Since SST analogs affect glucose metabolism, if previously normoglycemic patients experience increases in their fasting blood glucose and meet the criteria for diabetes while on pasireotide, they start anti-diabetic treatment using metformin. The efficacy of metformin on hyperglycemia management is assessed at a landmark of 16 weeks.

\section{Conclusion and future prospects}

Clinical trials, retrospective studies and laboratory-based in vitro and in vivo studies suggest the efficacy of metformin as a growth inhibitory agent in endocrine tumors (Tables 1 and 2). Most clinical observations that demonstrate the usefulness of metformin treatment in endocrine tumors is derived from diabetic patients who were taking metformin. With regard to DTC and pNETs, there are substantial data suggesting the therapeutic effects of metformin in these cancers. This promising epidemiological and preclinical evidence led to the initiation of phase II $(n=2)$ and phase $1(n=1)$ clinical trials using metformin as monotherapy or adjuvant treatment in the management of NETs. Besides this, a small randomized clinical trial testing the efficacy of metformin use on the volume of benign thyroid nodules is also underway. For other endocrine malignancies, there is either limited or no clinical data demonstrating the efficacy of metformin. For MTC, ATC, PA, PCC/PGL and ACC, evidence for the potential anti-cancer role of metformin originate from a small number of cell line studies. For the remaining endocrine malignancies, the effects of metformin have never been investigated. To evaluate the effects of metformin on these rare forms of endocrine cancers, it is important to create good cell line and mouse models. These preclinical studies can form the basis for clinical trials, where the effects of metformin can be analyzed on the patient population.

Another important question that must be addressed is the mechanism of action of metformin in different endocrine cancers. Current studies indicate multiple targets of metformin in cancer cells (Fig. 2). The most common 
Table 2 The table summarizes the effects of metformin on different endocrine tumors as reported in various preclinical studies.

Endocrine tumors

Thyroid cancer

Chen et al. 2012

Cho et al. 2014

PTC

Reference
Klubo-Gwiezdzinska et al.
2013

DTC

Thakur et al. 2018

PTC

Shen et al. 2017

Thyroid cancer

Kheder et al. 2017

Obesity-induced thyroid cancer

Park et al. 2016

Variable (0.1-20 mM)

Obesity-induced Park et al. 2018 thyroid cancer

(n)

Study design (cell lines)

In vitro study (FTC133, TPC1, BCPAP)

In vitro study (HTh74, HTh74Rdox, C643, SW1736, FTC133)

In vitro study (FTC133, BCPAP)

In vivo study (FTC133)

In vitro study (BCPAP, KTC1)

In vivo study (BCPAP)

In vivo study (ThrbPV/ PVPten+/-mice)

In vivo study (ThrbPV/PVPten+/mice)

\begin{tabular}{l} 
Metformin dose \\
\hline Variable $(0.5-5 \mathrm{mM})$
\end{tabular}

Variable (0.1-40 mM)

Variable $(0.1-40 \mathrm{mM})$

Variable $(10,50$, $100 \mathrm{mg} / \mathrm{mL}$ of metformin in drinking water for 30 days)

$5 \mathrm{mM}$

$12.5 \mathrm{mg}$ in water by oral gavage for 4 weeks

Variable (2.5-10 mM)

$300 \mathrm{mg} / \mathrm{kg} /$ day by intraperitoneal injections for a week Variable (0.03-20 mM) R082-W-1, 8305C, TT, Nthy-ori 3-1)

$\begin{array}{ll}\text { In vitro study (BCPAP, } & \text { Variable }(0.1-20 \mathrm{mM}) \\ \text { BHP10-3SC) } & \\ & \\ \text { In vivo study (BHP10-3SC) } & \text { Variable }(10,50, \\ & 100 \mathrm{mg} / \mathrm{mL} \text { of } \\ & \text { metformin in drinking } \\ \text { In vitro study (FTC133, BCPAP) } & \text { water for } 30 \text { days })\end{array}$

\begin{tabular}{l} 
Study endpoint \\
\hline Dose- and time- \\
dependent reduction in
\end{tabular} cellular proliferation in DTC cells

Metformin treatment inhibited cell proliferation, cell cycle progression and promoted apoptosis in thyroid cancer cells in a dose-dependent manner

Dose-dependent inhibition of cellular viability and induction of apoptosis in PTC cells

Dose-dependent reduction in tumor volume in PTC mouse model

Inhibition of cellular proliferation as well as mitochondrial respiration in DTC cells

Inhibition of tumor growth in a DTC mouse model characterized by high mGPDH expression Reduction in cellular viability and glucose uptake

Reduction in glucose uptake

Inhibition of cellular proliferation, migration and induction of apoptosis in a variety of thyroid cancer cell lines in a dosedependent manner

$0.5 \mathrm{mg} / \mathrm{mL}$ in drinking water

Inhibition of tumor progression by blocking vascular invasion and anaplasia in obesity-induced thyroid cancer mice models

$0.5 \mathrm{mg} / \mathrm{mL}$ in drinking water
Metformin, in combination with JQ1, led to a reduction in thyroid cancer growth and improved survival in obesity-induced thyroid cancer mice models 
Table 2 Continued.

$\begin{array}{ll}\text { Endocrine tumors } & \frac{\text { Reference }}{\text { Klubo-Gwiezdzinska }} \\ \text { et al. } 2012\end{array}$

$\frac{\overline{\text { Study design (cell lines) }}}{\text { In vitro study (TT and MZ-CRC-1) }}$

\section{Metformin dose}

Variable (0.5-5 mM)

In vitro study (SW1736, C643, 8305C)

Variable (2.5-60 mM)

ATC

Nozhat et al. 2018

Chen et al. 2015

In vitro study (HTh7, HTh74Rdox) 5 mM

ATC

Hanly et al. 2015

NET

PNET

PCC

PGL

ACC

Poli et al. 2016

Herrera-Martínez et al. 2019

Li et al. 2017

Florio et al. 2018

PitNETS

An et al. 2017

In vivo study (GH3)

PitNETs

Faggi et al. 2018

Vázquez-Borrego et al. 2019

Pituitary corticotroph tumor
In vivo study (H295R)

In vitro study (GH3)

In vitro study (Nthy-ori 3, BCPAP, $2 \mathrm{mM}$ 8505c)

$\begin{array}{ll}\text { In vitro study (PTJ64i and PTJ86i) } & \text { Variable (5-40 mM) } \\ \text { In vitro study (H295R, SW13) } & \text { Variable (0.5-250 mM) }\end{array}$

$\begin{array}{ll}\text { In vitro study (BON1, QGP-1) } & 10 \mathrm{mM} \\ \text { In vitro study (PC12) } & \text { Variable }(1-50 \mathrm{mM})\end{array}$

PitNETS

In vitro study (GH3)

In vitro study (primary culture on

ACTH-secreting adenomas,

non-functioning pituitary

adenomas, GH-secreting

adenomas, prolactinomas; cell

lines - AtT20, GH3)

In vitro study (AtT20)

Jin et al. 2018
$3 \mathrm{mg} / 100 \mu \mathrm{L}$ PBS for 40 days

Variable (2-50 mM)

Variable (0.1-10 mM)

$10 \mathrm{mM}$

Variable (1-50 mM)

Variable (0.5-250 mM)

Variable $(100,300$, $500 \mathrm{mg} / \mathrm{kg}$ for 4 weeks)

Variable (0.4-5 mM)

$5 \mathrm{mM}, 10 \mathrm{mM}$ 


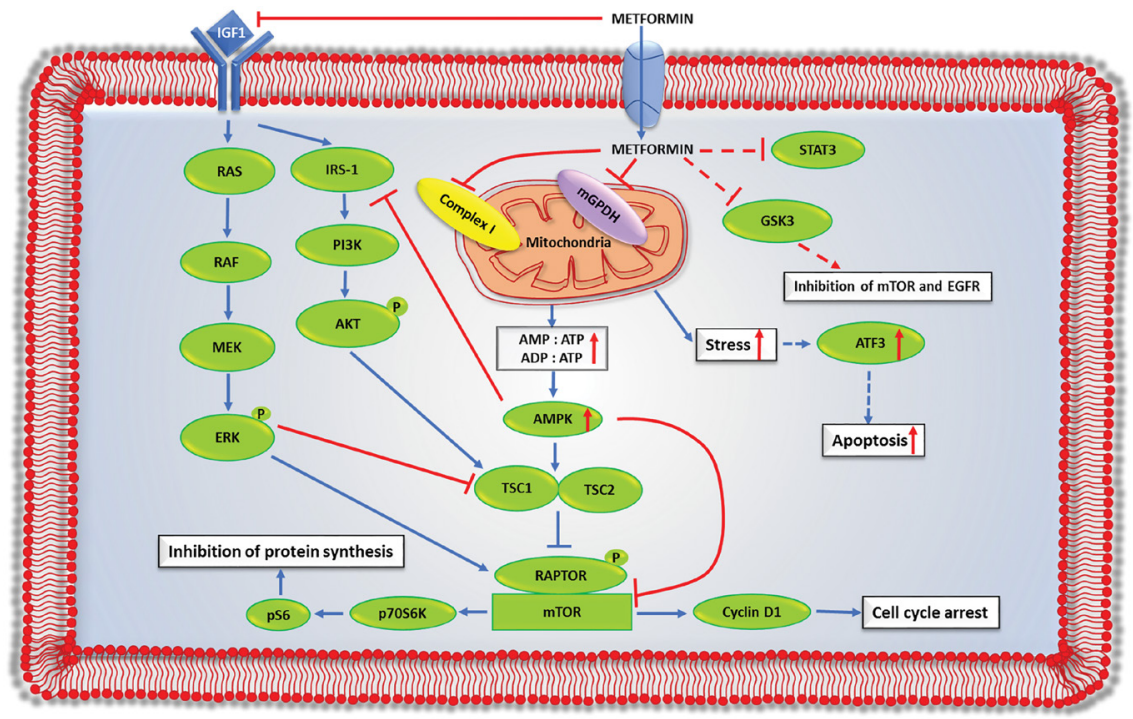

\section{Figure 2}

Mechanism of action of metformin in endocrine tumors: metformin is a negatively charged molecule that enters the cell through organic cation transporters (OCTs). After entering the cells, it can inhibit tumorigenesis through the following pathways. First, metformin, through its direct action, can inhibit complex 1 or mGPDH, either alone or together, to inhibit oxidative phosphorylation (OXPHOS). This inhibition of OXPHOS lowers the energy production (ATP synthesis) within the cells, which creates cellular stress in cancer cells. The reduction in ATP production increases both the AMP:ATP and ADP:ATP ratios, which activates AMPK. Activation of AMPK, in turn, leads to activation of tuberous sclerosis complex $1 / 2$ (TSC 1/2), which inhibits the mTOR pathway. Second, metformin can inhibit insulin or insulin-like growth factor-1 (IGF-1)-mediated activation of the RAS-MEK-ERK and PI3K-AKT pathways, which results in the inhibition of the mTOR pathway. Third, metformin-mediated activation of AMPK can inhibit phosphorylation of insulin receptor substrate-1 (IRS-1). IRS-1 is downstream of the IGF-1 pathway and upstream of the PI3K-AKT pathway. Inhibition of IRS-1 activity hampers AKT phosphorylation, which causes activation of the TSC complex and inhibition of the mTOR pathway. Last, metformin has other targets including STAT3, GSK3, and ATF3 in endocrine cells, but the exact pathway by which metformin targets these genes/proteins are not known.

mechanism by which metformin controls tumorigenesis includes inhibition of mitochondrial function by hindering complex I activity and AMPK-dependent and/or independent inhibition of the mTOR signaling pathway. Based on the available information from limited studies, the mechanism of action of metformin appears to be varied among different endocrine cancers. Besides the well-known targets, various additional metformin targets (e.g. mGPDH, ATF3, STAT3, GSK3, cyclins) have been identified in endocrine cancers. The exact mechanism by which metformin controls the action of these genes/ proteins are not known and must be elucidated. Metformin treatment can also inhibit the insulin/IGF-1 signaling pathway, which is associated with cellular proliferation. Moreover, metformin can also decrease the production of certain growth-promoting hormones, such as TSH and $\mathrm{GH}$, which could further contribute to the reduction of TSH- and GH-dependent tumors.

One of the most important points of consideration in the preclinical studies reporting the anti-cancer effects is the metformin doses and their translational relevance in humans. The plasma levels of metformin in patients taking therapeutic doses range from 10 to $40 \mu \mathrm{M}$; however, metformin concentration in the portal vein is much higher and ranges from 40 to $70 \mu \mathrm{M}$ (Song 2016). Considering the plasma and portal vein levels of metformin, the majority of the in vitro studies utilized supra-therapeutic doses of metformin, and thus, the effect size seen in vitro might not translate to the in vivo findings in humans (Table 2). However, it is important to note here that metformin accumulates in the cells and tissues over time, leading to a significant, several folds increase in its concentration within the cells compared to plasma levels (Rena et al. 2017). The accumulation of metformin within the cells depends on the surface expression of the transporters like organic cation transporters (OCTs), multidrug and toxin extruders (MATEs) and plasma membrane monoamine transporters (PMATs) (McCreight et al. 2016). The presence of OCTs in the liver results in 3-5 times higher accumulation of metformin within the hepatocytes than the portal vein. The concentration of metformin in the gut has been observed to be 30-300 times higher than the plasma concentrations (Song 2016). That being said, the supraphysiological concentrations of metformin used for the in vitro studies cannot be 
achieved in humans without potential toxicity. To establish the role of metformin in the management of endocrine tumors, it is important to validate the in vitro findings through preclinical studies at concentrations that can be translated into humans. Most of the in vivo studies were performed at doses leading to plasma concentration of metformin in animals comparable to the metformin levels in the plasma of the humans upon administration of therapeutic doses. These studies are, however, very limited in number and lack the information about metformin levels in the tumor tissues which is an important factor in determining the efficacy of metformin as an anti-cancer drug.

Another important point that draws attention in these preclinical studies is that the metformin-associated growth inhibitory effects are primarily due to inhibition of proliferation, rather than induction of massive apoptosis or necrosis, suggesting that monotherapy with metformin will not lead to complete remission of the tumor. Therefore, utilization of metformin as an adjunct to other treatment modalities has emerged as a promising strategy. Numerous studies have exploited metformin in synergy with standard treatment or in combination with other drugs for the treatment of different types of cancer and have observed a better response than the use of metformin alone. However, the mechanisms of synergy between metformin and other anti-cancer agents are not well understood and must be elucidated further to guide well-designed prospective trials on combination therapies in endocrine malignancies. Furthermore, additional studies are needed to identify biomarkers and patients' characteristics that are associated with the highest likelihood of response to metformin treatment in endocrine tumors.

A number of retrospective studies reported reduction in cancer incidence and progression of endocrine cancer. However, a retrospective design of these studies was associated with a significant inherent selection, information and immortal-time bias, unavailability of relevant information of all potential confounders, relatively small sample size and highly variable dosing and duration of metformin treatment. To overcome these limitations, it is important to conduct well-designed prospective clinical trials that can take into account all these factors.

Overall, although there are several limitations in studies investigating the role of metformin in endocrine cancers, metformin appears to be a promising adjuvant agent in the treatment of endocrine malignancies.

\section{Declaration of interest}

The authors declare that there is no conflict of interest that could be perceived as prejudicing the impartiality of this review.

\section{Funding}

NIDDK intramural funding program ZIA DK07514002.

\section{References}

Accardo G, Conzo G, Esposito D, Gambardella C, Mazzella M, Castaldo F, Di Donna C, Polistena A, Avenia N, Colantuoni V, et al. 2017 Genetics of medullary thyroid cancer: an overview. International Journal of Surgery 41 (Supplement 1) S2-S6. (https://doi. org/10.1016/j.ijsu.2017.02.064)

Amin S, Lux A \& O'Callaghan F 2019 The journey of metformin from glycaemic control to mTOR inhibition and the suppression of tumour growth. British Journal of Clinical Pharmacology 85 37-46. (https://doi.org/10.1111/bcp.13780)

An J, Pei X, Zang Z, Zhou Z, Hu J, Zheng X, Zhang Y, He J, Duan L, Shen R, et al. 2017 Metformin inhibits proliferation and growth hormone secretion of GH3 pituitary adenoma cells. Oncotarget 8 37538-37549. (https://doi.org/10.18632/oncotarget.16556)

Andrzejewski S, Siegel PM \& St-Pierre J 2018 Metabolic profiles associated with metformin efficacy in cancer. Frontiers in Endocrinology 9 372. (https://doi.org/10.3389/fendo.2018.00372)

Anil C, Kut A, Atesagaoglu B, Nar A, Bascil Tutuncu N \& Gursoy A 2016 Metformin decreases thyroid volume and nodule size in subjects with insulin resistance: a preliminary study. Medical Principles and Practice 25 233-236. (https://doi.org/10.1159/000442821)

Aristizabal Prada ET, Weis C, Orth M, Lauseker M, Spottl G, Maurer J, Grabowski P, Grossman A, Auernhammer CJ \& Nolting S 2018 GSK3alpha/beta: a novel therapeutic target for neuroendocrine tumors. Neuroendocrinology 106 335-351. (https://doi. org $/ 10.1159 / 000481887)$

Asa SL \& Mete O 2018 Endocrine pathology: past, present and future. Pathology 50 111-118. (https://doi.org/10.1016/j.pathol.2017.09.003)

Avalle L, Camporeale A, Camperi A \& Poli V 2017 STAT3 in cancer: a double edged sword. Cytokine 98 42-50. (https://doi.org/10.1016/j. cyto.2017.03.018)

Becker C, Jick SS, Meier CR \& Bodmer M 2015 No evidence for a decreased risk of thyroid cancer in association with use of metformin or other antidiabetic drugs: a case-control study. BMC Cancer 15719. (https://doi.org/10.1186/s12885-015-1719-6)

Bikas A, Van Nostrand D, Jensen K, Desale S, Mete M, Patel A, Wartofsky L, Vasko V \& Burman KD 2016 Metformin attenuates 131I-induced decrease in peripheral blood cells in patients with differentiated thyroid cancer. Thyroid 26 280-286. (https://doi. org/10.1089/thy.2015.0413)

Boelaert K 2009 The association between serum TSH concentration and thyroid cancer. Endocrine-Related Cancer 16 1065-1072. (https://doi. org/10.1677/ERC-09-0150)

Buscemi S, Massenti FM, Vasto S, Galvano F, Buscemi C, Corleo D, Barile AM, Rosafio G, Rini N \& Giordano C 2018 Association of obesity and diabetes with thyroid nodules. Endocrine 60 339-347. (https://doi.org/10.1007/s12020-017-1394-2)

Cabanillas ME, McFadden DG \& Durante C 2016 Thyroid cancer. Lancet 388 2783-2795. (https://doi.org/10.1016/S0140-6736(16)30172-6)

Chae YK, Arya A, Malecek MK, Shin DS, Carneiro B, Chandra S, Kaplan J, Kalyan A, Altman JK, Platanias L, et al. 2016 Repurposing metformin for cancer treatment: current clinical studies. Oncotarget 7 40767-40780. (https://doi.org/10.18632/oncotarget.8194) 
Chen G, Xu S, Renko K \& Derwahl M 2012 Metformin inhibits growth of thyroid carcinoma cells, suppresses self-renewal of derived cancer stem cells, and potentiates the effect of chemotherapeutic agents. Journal of Clinical Endocrinology and Metabolism 97 E510-E520. (https://doi.org/10.1210/jc.2011-1754)

Chen G, Nicula D, Renko K \& Derwahl M 2015 Synergistic antiproliferative effect of metformin and sorafenib on growth of anaplastic thyroid cancer cells and their stem cells. Oncology Reports 33 1994-2000. (https://doi.org/10.3892/or.2015.3805)

Cho SW, Yi KH, Han SK, Sun HJ, Kim YA, Oh BC, Park YJ \& Park DJ 2014 Therapeutic potential of metformin in papillary thyroid cancer in vitro and in vivo. Molecular and Cellular Endocrinology 393 24-29. (https://doi.org/10.1016/j.mce.2014.05.021)

Cho YY, Kang MJ, Kim SK, Jung JH, Hahm JR, Kim TH, Nam JY, Lee BW, Lee YH, Chung JH, et al. 2018 Protective effect of metformin against thyroid cancer development: a population-based study in Korea. Thyroid 28 864-870. (https://doi.org/10.1089/thy.2017.0550)

Choi YK \& Park KG 2013 Metabolic roles of AMPK and metformin in cancer cells. Molecules and Cells 36 279-287. (https://doi. org/10.1007/s10059-013-0169-8)

Dasari A, Shen C, Halperin D, Zhao B, Zhou S, Xu Y, Shih T \& Yao JC 2017 Trends in the incidence, prevalence, and survival outcomes in patients with neuroendocrine tumors in the United States. JAMA Oncology 3 1335-1342. (https://doi.org/10.1001/ jamaoncol.2017.0589)

DeLellis RA 2011 Parathyroid tumors and related disorders. Modern Pathology 24 (Supplement 2) S78-S93. (https://doi.org/10.1038/ modpathol.2010.132)

Dowling RJ, Niraula S, Stambolic V \& Goodwin PJ 2012 Metformin in cancer: translational challenges. Journal of Molecular Endocrinology 48 R31-R43. (https://doi.org/10.1530/JME-12-0007)

Duran AO, Anil C, Gursoy A, Nar A, Inanc M, Bozkurt O \& Tutuncu NB 2014 Thyroid volume in patients with glucose metabolism disorders. Arquivos Brasileiros de Endocrinologia e Metabologia 58 824-827. (https://doi.org/10.1590/0004-2730000003418)

Duran C, Sevinc B, Kutlu O \& Karahan O 2017 Parathyroidectomy decreases insulin resistance index in patients with primary hyperparathyroidism. Indian Journal of Surgery 79 101-105. (https:// doi.org/10.1007/s12262-015-1431-4)

Durante C, Grani G, Lamartina L, Filetti S, Mandel SJ \& Cooper DS 2018 The diagnosis and management of thyroid nodules: a review. JAMA 319 914-924. (https://doi.org/10.1001/jama.2018.0898)

Else T, Kim AC, Sabolch A, Raymond VM, Kandathil A, Caoili EM, Jolly S, Miller BS, Giordano TJ \& Hammer GD 2014 Adrenocortical carcinoma. Endocrine Reviews 35 282-326. (https://doi.org/10.1210/ er.2013-1029)

Faggi L, Giustina A \& Tulipano G 2018 Effects of metformin on cell growth and AMPK activity in pituitary adenoma cell cultures, focusing on the interaction with adenylyl cyclase activating signals. Molecular and Cellular Endocrinology 470 60-74. (https://doi. org/10.1016/j.mce.2017.09.030)

Fishbein L \& Nathanson KL 2012 Pheochromocytoma and paraganglioma: understanding the complexities of the genetic background. Cancer Genetics 205 1-11. (https://doi.org/10.1016/j. cancergen.2012.01.009)

Florio R, De Lellis L, Veschi S, Verginelli F, di Giacomo V, Gallorini M, Perconti S, Sanna M, Mariani-Costantini R, Natale A, et al. 2018 Effects of dichloroacetate as single agent or in combination with GW6471 and metformin in paraganglioma cells. Scientific Reports 8 13610. (https://doi.org/10.1038/s41598-018-31797-5)

Fournier JP, Yin H, Yu OH \& Azoulay L 2014 Metformin and low levels of thyroid-stimulating hormone in patients with type 2 diabetes mellitus. Canadian Medical Association Journal 186 1138-1145. (https://doi.org/10.1503/cmaj.140688)

Gandini S, Puntoni M, Heckman-Stoddard BM, Dunn BK, Ford L, DeCensi A \& Szabo E 2014 Metformin and cancer risk and mortality: a systematic review and meta-analysis taking into account biases and confounders. Cancer Prevention Research 7 867-885. (https://doi. org/10.1158/1940-6207.CAPR-13-0424)

Halfdanarson TR, Bamlet WR, McWilliams RR, Hobday TJ, Burch PA, Rabe KG \& Petersen GM 2014 Risk factors for pancreatic neuroendocrine tumors: a clinic-based case-control study. Pancreas 43 1219-1222. (https://doi.org/10.1097/MPA.0000000000000234)

Hanly EK, Bednarczyk RB, Tuli NY, Moscatello AL, Halicka HD, Li J, Geliebter J, Darzynkiewicz Z \& Tiwari RK 2015 mTOR inhibitors sensitize thyroid cancer cells to cytotoxic effect of vemurafenib. Oncotarget 6 39702-39713. (https://doi.org/10.18632/ oncotarget.4052)

Hassan MM, Phan A, Li D, Dagohoy CG, Leary C \& Yao JC 2008 Risk factors associated with neuroendocrine tumors: A U.S.-based casecontrol study. International Journal of Cancer 123 867-873. (https:// doi.org/10.1002/ijc.23529)

Haugvik SP, Hedenstrom P, Korsaeth E, Valente R, Hayes A, Siuka D, Maisonneuve P, Gladhaug IP, Lindkvist B \& Capurso G 2015 Diabetes, smoking, alcohol use, and family history of cancer as risk factors for pancreatic neuroendocrine tumors: a systematic review and meta-analysis. Neuroendocrinology 101 133-142. (https://doi. org/10.1159/000375164)

Hawkes AL, Quinn M, Gebski V, Armes J, Brennan D, Janda M, feMME Trial Committee \& Obermair A 2014 Improving treatment for obese women with early stage cancer of the uterus: rationale and design of the levonorgestrel intrauterine device +/- metformin +/- weight loss in endometrial cancer (feMME) trial. Contemporary Clinical Trials 39 14-21. (https://doi.org/10.1016/j.cct.2014.06.014)

He X, Wu D, Hu C, Xu T, Liu Y, Liu C, Xu B \& Tang W 2019 Role of metformin in the treatment of patients with thyroid nodules and insulin resistance: a systematic review and meta-analysis. Thyroid 29 359-367. (https://doi.org/10.1089/thy.2017.0707)

Herrera-Martínez AD, Pedraza-Arevalo S, L-López F, Gahete MD, GálvezMoreno MA, Castaño JP \& Luque RM 2019 Type 2 diabetes in neuroendocrine tumors: are biguanides and statins part of the solution? Journal of Clinical Endocrinology and Metabolism 104 57-73. (https://doi.org/10.1210/jc.2018-01455)

Jang EK, Kim WG, Kwon H, Choi YM, Jeon MJ, Kim TY, Shong YK, Kim WB \& Kim EY 2015 Metformin is associated with a favorable outcome in diabetic patients with cervical lymph node metastasis of differentiated thyroid cancer. European Thyroid Journal 4 181-188. (https://doi.org/10.1159/000437365)

Jin K, Ruan L, Pu J, Zhong A, Wang F, Tan S, Huang H, Mu J \& Yang G 2018 Metformin suppresses growth and adrenocorticotrophic hormone secretion in mouse pituitary corticotroph tumor AtT20 cells. Molecular and Cellular Endocrinology 478 53-61. (https://doi. org/10.1016/j.mce.2018.07.007)

Karimifar M, Aminorroaya A, Amini M, Mirfendereski T, Iraj B, Feizi A \& Norozi A 2014 Effect of metformin on thyroid stimulating hormone and thyroid volume in patients with prediabetes: a randomized placebo-controlled clinical trial. Journal of Research in Medical Sciences 19 1019-1026.

Kheder S, Sisley K, Hadad S \& Balasubramanian SP 2017 Effects of prolonged exposure to low dose metformin in thyroid cancer cell lines. Journal of Cancer 8 1053-1061. (https://doi.org/10.7150/jca.16584)

Kitahara CM, Platz EA, Freeman LE, Hsing AW, Linet MS, Park Y, Schairer C, Schatzkin A, Shikany JM \& Berrington de Gonzalez A 2011 Obesity and thyroid cancer risk among U.S. men and women: a pooled analysis of five prospective studies. Cancer Epidemiology, Biomarkers and Prevention 20 464-472. (https://doi.org/10.1158/10559965.EPI-10-1220)

Klubo-Gwiezdzinska J, Jensen K, Costello J, Patel A, Hoperia V, Bauer A, Burman KD, Wartofsky L \& Vasko V 2012 Metformin inhibits growth and decreases resistance to anoikis in medullary thyroid cancer cells. Endocrine-Related Cancer 19 447-456. (https://doi. org/10.1530/ERC-12-0046) 
Klubo-Gwiezdzinska J, Costello J, Jr, Patel A, Bauer A, Jensen K, Mete M, Burman KD, Wartofsky L \& Vasko V 2013 Treatment with metformin is associated with higher remission rate in diabetic patients with thyroid cancer. Journal of Clinical Endocrinology and Metabolism 98 3269-3279. (https://doi.org/10.1210/jc.2012-3799)

Lee CK, Jung M, Jung I, Heo SJ, Jeong YH, An JY, Kim HI, Cheong JH, Hyung WJ, Noh SH, et al. 2016 Cumulative metformin use and its impact on survival in gastric cancer patients after gastrectomy. Annals of Surgery 263 96-102. (https://doi.org/10.1097/ SLA.0000000000001086)

Lei Y, Yi Y, Liu Y, Liu X, Keller ET, Qian CN, Zhang J \& Lu Y 2017 Metformin targets multiple signaling pathways in cancer. Chinese Journal of Cancer 36 17. (https://doi.org/10.1186/s40880017-0184-9)

Li H \& Qian J 2017 Association of diabetes mellitus with thyroid cancer risk: a meta-analysis of cohort studies. Medicine 96 e8230. (https:// doi.org/10.1097/MD.0000000000008230)

Li M, Jiang X, Su T, Jiang L, Zhou W \& Wang W 2017 Metformin suppresses proliferation and viability of rat pheochromocytoma cells. Medical Science Monitor 23 3253-3260. (https://doi.org/10.12659/ msm.903348)

Li M, Li X, Zhang H \& Lu Y 2018 Molecular mechanisms of metformin for diabetes and cancer treatment. Frontiers in Physiology 91039. (https://doi.org/10.3389/fphys.2018.01039)

Lima CR, Gomes CC \& Santos MF 2017 Role of microRNAs in endocrine cancer metastasis. Molecular and Cellular Endocrinology 456 62-75. (https://doi.org/10.1016/j.mce.2017.03.015)

Limaiem F \& Giwa AO 2019 Cancer, anaplastic thyroid. In StatPearls. Treasure Island, FL, USA: StatPearls Publishing. (available at: https:// www.ncbi.nlm.nih.gov/books/NBK538179/)

Liu X, Liu Y, Gao J, Feng M, Bao X, Deng K, Yao Y \& Wang R 2018 Combination treatment with bromocriptine and metformin in patients with bromocriptine-resistant prolactinomas: pilot study. World Neurosurgery 115 94-98. (https://doi.org/10.1016/j. wneu.2018.02.188)

Madiraju AK, Erion DM, Rahimi Y, Zhang XM, Braddock DT, Albright RA, Prigaro BJ, Wood JL, Bhanot S, MacDonald MJ, et al. 2014 Metformin suppresses gluconeogenesis by inhibiting mitochondrial glycerophosphate dehydrogenase. Nature $\mathbf{5 1 0}$ 542-546. (https://doi.org/10.1038/nature13270)

Mancinelli R, Carpino G, Petrungaro S, Mammola CL, Tomaipitinca L, Filippini A, Facchiano A, Ziparo E \& Giampietri C 2017 Multifaceted roles of GSK-3 in cancer and autophagy-related diseases. Oxidative Medicine and Cellular Longevity 2017 4629495. (https://doi. org/10.1155/2017/4629495)

McCreight LJ, Bailey CJ \& Pearson ER 2016 Metformin and the gastrointestinal tract. Diabetologia 59 426-435. (https://doi. org/10.1007/s00125-015-3844-9)

Mehta GU \& Lonser RR 2017 Management of hormone-secreting pituitary adenomas. Neuro-Oncology 19 762-773. (https://doi. org/10.1093/neuonc/now130)

Meireles C, Neves F, Simeoni L \& Lofrano-Porto A 2017 Metformin reduces viability and proliferation of pheochromocytoma cells in vitro. Presented at the 19th European Congress of Endocrinology, ECE 2017, Lisbon, Portugal. Endocrine Abstracts 49 GP26. (https:// doi.org/10.1530/endoabs.49.GP26)

Mendoza MC, Er EE \& Blenis J 2011 The Ras-ERK and PI3K-mTOR pathways: cross-talk and compensation. Trends in Biochemical Sciences 36 320-328. (https://doi.org/10.1016/j.tibs.2011.03.006)

Moon JH, Hyun MK, Lee JY, Shim JI, Kim TH, Choi HS, Ahn HY, Kim KW, Park DJ, Park YJ, et al. 2018 Prevalence of thyroid nodules and their associated clinical parameters: a large-scale, multicenterbased health checkup study. Korean Journal of Internal Medicine 33 753-762. (https://doi.org/10.3904/kjim.2015.273)

Motoshima H, Goldstein BJ, Igata M \& Araki E 2006 AMPK and cell proliferation - AMPK as a therapeutic target for atherosclerosis and cancer. Journal of Physiology 574 63-71. (https://doi.org/10.1113/ jphysiol.2006.108324)

Mousavi Z, Dourandish L, Rokni H, Sadeghi R \& Rasoul Zakavi S 2014 Effects of short-term metformin therapy associated with levothyroxine dose decrement on TSH and thyroid hormone levels in patients with thyroid cancer. Minerva Endocrinologica 39 59-65.

Mracek T, Drahota Z \& Houstek J 2013 The function and the role of the mitochondrial glycerol-3-phosphate dehydrogenase in mammalian tissues. Biochimica and Biophysica Acta 1827 401-410. (https://doi. org/10.1016/j.bbabio.2012.11.014)

Nayan M, Bhindi B, Yu JL, Hermanns T, Mohammed A, Hamilton RJ, Finelli A, Jewett MA, Zlotta AR, Fleshner NE, et al. 2015 The effect of metformin on cancer-specific survival outcomes in diabetic patients undergoing radical cystectomy for urothelial carcinoma of the bladder. Urologic Oncology 33 386.e7-386.e13. (https://doi. org/10.1016/j.urolonc.2015.05.024)

Niraula S, Dowling RJ, Ennis M, Chang MC, Done SJ, Hood N, Escallon J, Leong WL, McCready DR, Reedijk M, et al. 2012 Metformin in early breast cancer: a prospective window of opportunity neoadjuvant study. Breast Cancer Research and Treatment 135 821-830. (https://doi.org/10.1007/s10549-012-2223-1)

Nozhat Z, Mohammadi-Yeganeh S, Azizi F, Zarkesh M \& Hedayati M 2018 Effects of metformin on the PI3K/AKT/FOXO1 pathway in anaplastic thyroid cancer cell lines. Daru 26 93-103. (https://doi. org/10.1007/s40199-018-0208-2)

Oronsky B, Ma PC, Morgensztern D \& Carter CA 2017 Nothing but NET: a review of neuroendocrine tumors and carcinomas. Neoplasia 19 991-1002. (https://doi.org/10.1016/j.neo.2017.09.002)

Park J, Kim WG, Zhao L, Enomoto K, Willingham M \& Cheng SY 2016 Metformin blocks progression of obesity-activated thyroid cancer in a mouse model. Oncotarget 7 34832-34844. (https://doi. org/10.18632/oncotarget.8989)

Park S, Willingham MC, Qi J \& Cheng SY 2018 Metformin and JQ1 synergistically inhibit obesity-activated thyroid cancer. EndocrineRelated Cancer 25 865-877. (https://doi.org/10.1530/ERC-18-0071)

Patel P \& Galoian K 2018 Molecular challenges of neuroendocrine tumors. Oncology Letters 15 2715-2725. (https://doi.org/10.3892/ ol.2017.7680)

Peixoto RD, Gomes LM, Sousa TT, Racy DJ, Shigenaga M \& Nagourney RA 2018 Efficacy of oral metformin in a patient with metastatic adrenocortical carcinoma: examination of mechanisms and therapeutic implications. Rare Tumors 10 [epub]. (https://doi. org/10.1177/2036361317749645)

Pierotti MA, Berrino F, Gariboldi M, Melani C, Mogavero A, Negri T, Pasanisi P \& Pilotti S 2013 Targeting metabolism for cancer treatment and prevention: metformin, an old drug with multifaceted effects. Oncogene 32 1475-1487. (https://doi.org/10.1038/ onc.2012.181)

Plews RL, Mohd Yusof A, Wang C, Saji M, Zhang X, Chen CS, Ringel MD \& Phay JE 2015 A novel dual AMPK activator/mTOR inhibitor inhibits thyroid cancer cell growth. Journal of Clinical Endocrinology and Metabolism 100 E748-E756. (https://doi. org/10.1210/jc.2014-1777)

Poli G, Cantini G, Armignacco R, Fucci R, Santi R, Canu L, Nesi G, Mannelli M \& Luconi M 2016 Metformin as a new anti-cancer drug in adrenocortical carcinoma. Oncotarget 7 49636-49648. (https://doi. org/10.18632/oncotarget.10421)

Pusceddu S, Buzzoni R, Vernieri C, Concas L, Marceglia S, Giacomelli L, Milione M, Leuzzi L, Femia D, Formisano B, et al. 2016 Metformin with everolimus and octreotide in pancreatic neuroendocrine tumor patients with diabetes. Future Oncology 12 1251-1260. (https://doi. org/10.2217/fon-2015-0077)

Pusceddu S, Vernieri C, Di Maio M, Marconcini R, Spada F, Massironi S, Ibrahim T, Brizzi MP, Campana D, Faggiano A, et al. 2018 Metformin use is associated with longer progression-free survival of patients with diabetes and pancreatic neuroendocrine tumors receiving 
everolimus and/or somatostatin analogues. Gastroenterology 155479. e7-489.e7. (https://doi.org/10.1053/i.gastro.2018.04.010)

Rena G, Hardie DG \& Pearson ER 2017 The mechanisms of action of metformin. Diabetologia 60 1577-1585. (https://doi.org/10.1007/ s00125-017-4342-z)

Rezzonico JN, Rezzonico M, Pusiol E, Pitoia F \& Niepomniszcze H 2009 Increased prevalence of insulin resistance in patients with differentiated thyroid carcinoma. Metabolic Syndrome and Related Disorders 7 375-380. (https://doi.org/10.1089/met.2008.0062)

Rezzonico J, Rezzonico M, Pusiol E, Pitoia F \& Niepomniszcze H 2011 Metformin treatment for small benign thyroid nodules in patients with insulin resistance. Metabolic Syndrome and Related Disorders 9 69-75. (https://doi.org/10.1089/met.2010.0026)

Saini N \& Yang X 2018 Metformin as an anti-cancer agent: actions and mechanisms targeting cancer stem cells. Acta Biochimica et Biophysica Sinica 50 133-143. (https://doi.org/10.1093/abbs/gmx106)

Saini S, Tulla K, Maker AV, Burman KD \& Prabhakar BS 2018 Therapeutic advances in anaplastic thyroid cancer: a current perspective. Molecular Cancer 17 154. (https://doi.org/10.1186/ s12943-018-0903-0)

Schmidbauer B, Menhart K, Hellwig D \& Grosse J 2017 Differentiated thyroid cancer-treatment: state of the art. International Journal of Molecular Sciences 18 E1292. (https://doi.org/10.3390/ijms18061292)

Schulten HJ 2018 Pleiotropic effects of metformin on cancer. International Journal of Molecular Sciences 19 E2850. (https://doi. org/10.3390/ijms19102850)

Sharma M, Aronow WS, Patel L, Gandhi K \& Desai H 2011 Hyperthyroidism. Medical Science Monitor 17 RA85-RA91. (https:// doi.org/10.12659/msm.881705)

Shen CT, Wei WJ, Qiu ZL, Song HJ, Zhang XY, Sun ZK \& Luo QY 2017 Metformin reduces glycometabolism of papillary thyroid carcinoma in vitro and in vivo. Journal of Molecular Endocrinology 58 15-23. (https://doi.org/10.1530/JME-16-0134)

Song R 2016 Mechanism of metformin: a tale of two sites. Diabetes Care 39 187-189. (https://doi.org/10.2337/dci15-0013)

Sosnicki S, Kapral M \& Weglarz L 2016 Molecular targets of metformin antitumor action. Pharmacological Reports 68 918-925. (https://doi. org/10.1016/j.pharep.2016.04.021)

Spillane S, Bennett K, Sharp L \& Barron TI 2013 A cohort study of metformin exposure and survival in patients with stage I-III colorectal cancer. Cancer Epidemiology, Biomarkers and Prevention 22 1364-1373. (https://doi.org/10.1158/1055-9965.EPI-13-0347)

Subbiah V, Kreitman RJ, Wainberg ZA, Cho JY, Schellens JHM, Soria JC, Wen PY, Zielinski C, Cabanillas ME, Urbanowitz G, et al. 2018 Dabrafenib and trametinib treatment in patients with locally advanced or metastatic BRAF V600-mutant anaplastic thyroid cancer. Journal of Clinical Oncology 36 7-13. (https://doi.org/10.1200/ JCO.2017.73.6785)

Sui M, Yu Y, Zhang H, Di H, Liu C \& Fan Y 2018 Efficacy of metformin for benign thyroid nodules in subjects with insulin resistance: a systematic review and meta-analysis. Frontiers in Endocrinology 9494. (https://doi.org/10.3389/fendo.2018.00494)

Tanaka R, Tsushima T, Murakami H, Shizume K \& Obara T 1994 Insulinlike growth factor I receptors and insulin-like growth factor-binding proteins in human parathyroid tumors. World Journal of Surgery 18 635-641; discussion 641-632. (https://doi.org/10.1007/BF00353784)

Tang Y, Yan T, Wang G, Chen Y, Zhu Y, Jiang Z, Yang M, Li C, Li Z, Yu P, et al. 2017 Correlation between insulin resistance and thyroid nodule in type 2 diabetes mellitus. International Journal of Endocrinology 2017 1617458. (https://doi.org/10.1155/2017/1617458)

Thakker RV 2016 Genetics of parathyroid tumours. Journal of Internal Medicine 280 574-583. (https://doi.org/10.1111/joim.12523)

Thakur S, Daley B, Gaskins K, Vasko VV, Boufraqech M, Patel D, Sourbier C, Reece J, Cheng SY, Kebebew E, et al. 2018 Metformin targets mitochondrial glycerophosphate dehydrogenase to control rate of oxidative phosphorylation and growth of thyroid cancer in vitro and in vivo. Clinical Cancer Research 24 4030-4043. (https:// doi.org/10.1158/1078-0432.CCR-17-3167)

Theodros D, Patel M, Ruzevick J, Lim M \& Bettegowda C 2015 Pituitary adenomas: historical perspective, surgical management and future directions. CNS Oncology 4 411-429. (https://doi.org/10.2217/ cns.15.21)

Tseng CH 2014 Metformin reduces thyroid cancer risk in Taiwanese patients with type 2 diabetes. PLOS ONE 9 e109852. (https://doi. org/10.1371/journal.pone.0109852)

Vancura A, Bu P, Bhagwat M, Zeng J \& Vancurova I 2018 Metformin as an anticancer agent. Trends in Pharmacological Sciences 39 867-878. (https://doi.org/10.1016/j.tips.2018.07.006)

Vázquez-Borrego MC, Fuentes-Fayos AC, Herrera-Martínez AD, L-López F, Ibáñez-Costa A, Moreno-Moreno P, Alhambra-Expósito MR, BarreraMartín A, Blanco-Acevedo C, Dios E, et al. 2019 Biguanides exert antitumoral actions in pituitary tumor cells through AMPKdependent and -independent mechanisms. Journal of Clinical Endocrinology and Metabolism 104 3501-3513. (https://doi. org/10.1210/jc.2019-00056)

Vella V, Sciacca L, Pandini G, Mineo R, Squatrito S, Vigneri R \& Belfiore A 2001 The IGF system in thyroid cancer: new concepts. Molecular Pathology 54 121-124. (https://doi.org/10.1136/ mp.54.3.121)

Vigneri P, Frasca F, Sciacca L, Pandini G \& Vigneri R 2009 Diabetes and cancer. Endocrine-Related Cancer 16 1103-1123. (https://doi. org/10.1677/ERC-09-0087)

Vlotides G, Tanyeri A, Spampatti M, Zitzmann K, Chourdakis M, Spttl C, Maurer J, Nölting S, Göke B \& Auernhammer CJ 2014 Anticancer effects of metformin on neuroendocrine tumor cells in vitro. Hormones 13 498-508. (https://doi.org/10.14310/horm.2002.1517)

Yin X, Dewille JW \& Hai T 2008 A potential dichotomous role of ATF3, an adaptive-response gene, in cancer development. Oncogene $\mathbf{2 7}$ 2118-2127. (https://doi.org/10.1038/sj.onc.1210861)

Yin M, Zhou J, Gorak EJ \& Quddus F 2013 Metformin is associated with survival benefit in cancer patients with concurrent type 2 diabetes: a systematic review and meta-analysis. Oncologist 18 1248-1255. (https://doi.org/10.1634/theoncologist.2013-0111)

Young K, Iyer R, Morganstein D, Chau I, Cunningham D \& Starling N 2015 Pancreatic neuroendocrine tumors: a review. Future Oncology 11 853-864. (https://doi.org/10.2217/fon.14.285)

Zakikhani M, Blouin MJ, Piura E \& Pollak MN 2010 Metformin and rapamycin have distinct effects on the AKT pathway and proliferation in breast cancer cells. Breast Cancer Research and Treatment 123 271-279. (https://doi.org/10.1007/s10549-010-0763-9)

Zhang Y \& Nose V 2011 Endocrine tumors as part of inherited tumor syndromes. Advances in Anatomic Pathology 18 206-218. (https://doi. org/10.1097/PAP.0b013e3182169916)

Zhou J, Massey S, Story D \& Li L 2018 Metformin: an old drug with new applications. International Journal of Molecular Sciences 19. (https:// doi.org/10.3390/ijms19102863)

Received in final form 28 June 2019

Accepted 15 July 2019

Accepted Preprint published online 15 July 2019 https://jme.bioscientifica.com https://doi.org/10.1530/JME-19-0083 (c) 2019 Society for Endocrinology Published by Bioscientifica Ltd. Printed in Great Britain 